\title{
Key Lessons for the Design of Consumer Protection Legislation
}

\author{
Shmuel I. Becher*
}

Abstract

Legislation, even when well-intended, sometimes fails to provide the desired results. By design, the legislative process suffers from "noise" and is typically driven by diverse motives. Inevitably, then, the legislative process generates some mistakes.

In spite of these mistakes, the legal discussion of the mechanics of the legislative process is partial and underdeveloped. Focusing on consumer protection legislation, this chapter aims to fill some of this gap. It makes two complementary arguments. Descriptively, the chapter succinctly points to some predominant weaknesses in the legislative process. It illustrates how consumer protection laws may not only fail to achieve their desired results but can also backfire and harm consumers. Normatively and prescriptively, the chapter calls for a nuanced and holistic attitude to consumer protection legislation. It argues for more cautious and tailored consumer protection legislation, which benefits from healthy skepticism.

The chapter identifies four principles for improving the process of consumer law-making. First is a more careful approach to legislation, where legislatures progress in a gradual and moderate way. The second proposed principle is to approach the legislative process from a multidisciplinary, evidence-based, empirical perspective. The third principle suggests adopting a humble decision-making process, which employs temporary consumer protection laws. Finally, the fourth principle offers diffusing and delegating some, or perhaps more, legislative and policy responsibility to administrative agencies and consumer organisations.

The chapter draws on consumer protection examples from Europe, North America, Australia, New Zealand and Israel. However, it is largely general in nature. If proven successful, the proposed design principles may be scaled up and implemented in additional jurisdictions and other domains.

\section{Introduction}

Legislation, even when well-intended, sometimes fails to provide the desired results. The legislative process suffers from "noise" and is not an exact science. By design, it is typically influenced by various players and driven by diverse motives. Inevitably, then, the legislative process generates some mistakes.

In spite of these detrimental mistakes, the legal discussion of the mechanics of the legislative process is partial and underdeveloped. The legal literature does not sufficiently address means to improve the design issues that often lead to legislative mistakes. Focusing on consumer protection legislation, this chapter aims to fill some of this gap.

\footnotetext{
* Victoria University of Wellington; LL.M., J.S.D (Yale University). This chapter draws on my previous work, and especially on Becher S (2018) Unintended Consequences and the Design of Consumer Protection Legislation. Tulane Law Review 93:105-146.
} 
This chapter makes two complementary arguments. First, it shows how the process of legislating consumer protection laws is flawed and sometimes produces troublesome outcomes. Descriptively, Part 2 succinctly points to some predominant weaknesses in the legislative process. Thereafter, Part 3 illustrates how consumer protection laws may not only fail to achieve their desired results but can also backfire and harm consumers. This is dubbed the problem of unintended consequences.

Next, the chapter makes its second argument, calling for a nuanced and holistic attitude to consumer protection legislation. Normatively and prescriptively, this chapter argues for more cautious and tailored consumer protection legislation, which benefits from healthy skepticism. In particular, Part 4 identifies four principles for improving the process of consumer law-making. First, it suggests a more careful approach to legislation, where legislatures progress in a gradual and moderate way. Second, it recommends approaching the legislative process from a multidisciplinary, evidence-based, empirical perspective. Third, it suggests adopting a humble decisionmaking process which employs temporary consumer protection laws. Fourth, it recommends diffusing and delegating some, or perhaps more, legislative and policy responsibility to administrative agencies and consumer organisations.

This chapter draws on consumer protection related examples from Europe, North America, Australia, New Zealand and Israel. However, it is largely general in nature. If proven successful, the proposed approach may be scaled up and implemented in other domains and additional jurisdictions.

\section{Consumer Protection Legislation}

Various reasons can lead to sub-optimal consumer protection legislation. To begin, consumer protection legislation tackles numerous markets, failures and complex challenges. Policymakers and legislatures cannot be expected to possess the expertise required for tacking all these challenges efficiently. ${ }^{1}$ Simply put, it is unrealistic to assume that legislatures will have the relevant knowledge required to make optimal decisions. ${ }^{2}$ Thus, institutional limitations and lack of expertise render the legislative process prone to mistakes. ${ }^{3}$

The body of knowledge that humans possess is enormous and dynamic. Products, services, ideas and markets are developing at a pace we have never experienced before. Our understanding of consumers and their interests is also changing. We now have a better understanding that

\footnotetext{
1.Hayek (1945).

2.Schuck (2014).

3.Baxter (1994), p. 128.
} 
consumers are heterogeneous and have different preferences and responses-which makes consumer protection policy even more challenging. ${ }^{4}$

No doubt, it is hard for legislation to track all these developments and respond timely to economic, scientific and technological developments. Oftentimes, these developments were unforeseen at the time the policy or legislation was formulated. ${ }^{5}$ Indeed, legislatures will typically be too slow-moving and too rigid in their procedures, ${ }^{6}$ and firms will outsmart legislative efforts. ${ }^{7}$ Furthermore, policymakers may discard good ideas if such ideas are likely to be perceived as "extreme." ${ }^{8}$ At times, this may be due to the desire of policymakers to maintain their public image. ${ }^{9}$

At the same time, legislatures-like other decisionmakers-tend to be overly confident. ${ }^{10}$ They are likely to be swayed by cognitive biases. ${ }^{11}$ Among other things, they do not always admit complexity and are likely to overestimate their knowledge and capacity to make good choices.

Additionally, the legislative process is often influenced by interest groups, lobbying, and shortterm political considerations. In this regard, public choice (PC) theory provides an appealing lens through which to take account of these influences. This is especially true in the context of consumer protection legislation.

According to the PC framework, the legislative process can be viewed through a market lens. Legislation is mainly determined by demand patterns, ${ }^{12}$ which are assumed to be dominated by interest groups who may form coalitions. ${ }^{13}$ In our context, traders and firms can often cooperate and create well-organised and powerful interest groups. ${ }^{14}$ Business organisations represent strong and usually affluent interest groups, which can tentatively coordinate and achieve a great deal of influence on legislatures. ${ }^{15}$

4. Cf. Bar-Gill and Ben-Shahar (2013), p. 114.

5.Becher (2008), p. 759; Romano (2014), p. 27.

6. See generally Calabresi (1982).

7.Willis (2015), p. 1327.

8. Bregman (2014).

9. This relates to the "Overton Window". See Bregman (2014).

10. Chabris, Simons (2010).

11. Schuck (2014), p. 154-60.

12. Eskridge, Frickey, Garrett (2007); Stancil (2008).

13. Stancil (2008), p. 1277.

14. Eskridge, Frickey, Garrett (2007), p. 48-53.

15. Eskridge, Frickey, Garrett (2007), p. 50-51. 
Consumers, however, might suffer from "collective action" and the classic free-rider problem. ${ }^{16}$ They will find it complicated and time-consuming to coordinate their moves. Consumers, as individuals, are diffused and insufficiently incentivised to influence legislation. ${ }^{17}$ They might as well have heterogeneous and conflicting interests. ${ }^{18}$ This undermines consumers' ability to pressure legislatures. ${ }^{19}$ Finally, consumers might not have adequate resources for effective participation in the legislative process. ${ }^{20}$ Thus, consumers will not be properly represented in the legislative process and will find it difficult to counter the pressure that well-organised industry groups generate. ${ }^{21}$

With respect to the supply side of this market, PC theory predicts that legislatures will be motivated by their desire to be (re)elected. ${ }^{22}$ Given this structure, PC theory posits that legislatures are prone to enact statutes that concentrate benefits on specific interest groups. ${ }^{23} \mathrm{At}$ the same time, the costs associated with these statutes are likely to be distributed amongst the general public. ${ }^{24}$

Legislative initiatives aimed at empowering consumers are likely to reduce businesses' superiority over consumers. Businesses, thus, are likely to encounter such initiatives. At the same time, those policies that distribute benefits broadly on consumers are unlikely to be intensely supported and advanced by interest groups. ${ }^{25}$ Therefore, PC theory predicts that legislatures will supply too few consumer protection statutes that are publicly-inclined. ${ }^{26}$

As an illustration, consider the initiative to implement user-friendly front-of-package food health labelling. Such initiatives call for simplified and intuitive labelling schemes. Typically, the schemes employ colour-coded labels that provide consumers with a quick and easy way to assess the overall healthiness of foods. Examples include the UK traffic lights and the French Nutri-Score.

16. O’Connor (2001), p. 370; Gillette (2005), p. 1008.

17. Gillette (2005), p. 1007, n. 122; Gillette (1996), p. 196.

18. Letsou (1995).

19. Kripke (1982), p. 583.

20. Baxter (1994), p. 125; Boss (1994), p. 94; Rubin (1993), p. 761.

21. Rubin (1993), p. 787.

22. Eskridge, Frickey, Garrett (2007), p. 57.

23. Eskridge, Frickey, Garrett (2007), p. 57.

24. Eskridge, Frickey, Garrett (2007), p. 58.

25. Eskridge, Frickey, Garrett (2007), p. 59.

26. Eskridge, Frickey, Garrett (2007), p. 59. 
These, and other similar initiatives, have the potential to better consumers' food choices and thus, improve their health. Yet they have been failing miserably on the legislative front. As Goyens points out:

[...] compulsory front-of-pack nutrition labelling with colour coding was discussed in the context of the adoption of the Food Information to Consumers Regulation, but was eventually dropped due to heavy industry lobbying. Despite consumer praise for the clarity and usefulness of colour-coded schemes, industry has long fiercely opposed having a red mark on their products (due to the behavioural connotations connected with red as a symbol for danger). ${ }^{27}$

One may argue that consumers can nevertheless be well-represented by consumer organisations. Indeed, some consumer agencies and organisations successfully represent, advocate, and support consumers' interests. Nonetheless, consumer organisations are frequently less active and less effective when it comes to influencing consumer protection legislation. First, ex-ante legislation is often a way to prevent problems or minimise them. However, people often undervalue ex-ante prevention and overvalue ex-post treatment and intervention..$^{28}$ Prevention is future-oriented, does not have a clear and immediate manifestation, and is therefore an unappreciated job. Second, consumer organisations will typically have highly limited resources and are likely to find it too challenging to compete against traders. ${ }^{29}$ While industries can attract many of the brightest and sharpest minds with generous payments, high status and lavish working conditions, consumer organisations may find it harder to attract such minds. ${ }^{30}$

\section{The Problem of Unintended Consequences}

Consumer protection legislation is sometimes not only biased or ineffective but may also prove quite harmful. For starters, protective legislation may inflict greater costs on consumers than benefits. ${ }^{31}$ Ex ante regulatory protection often entails additional expenses to traders, who then pass these costs on to consumers. ${ }^{32}$

The problem of rolling costs on to consumers is a well-known concern. But there are other, more nuanced and less obvious, concerns that stem from the ways firms and consumers respond to legislation. Simply put, legal interventions-even well-intended-sometimes do not turn out as planned. A few examples of unintended consequences resulting from consumer protection legislation are briefly discussed next.

27. Goyens (2018), p. 16.

28. Sullivan, Behncke, Purushotham (2010).

29. Braucher (1988), p. 403; Silber (1997), p. 235.

30. Schuck (2014), p. 204.

31. Letsou (1995), p. 620.

32. Bar-Gill and Ben-Shahar (2013), p. 110. 


\subsection{Lending, Credit Regulation, and Price Caps}

Perhaps one of the most classic, yet debated, examples of unintended consequences is interest rate caps. At first sight, rate caps are a sensible response to unscrupulous traders who take advantage of vulnerable consumers by charging them excessive interest rates. Interest rates are often part of a manipulative, well-crafted scheme that capitalises on consumers' bounded rationality. ${ }^{33}$ Excessive interest rates may offend our sense of fairness.

However, capping interest rates may not be the optimal solution as doing so can make credit less available to borrowers. From an economic perspective, interest rates reflect risk. Poor consumers are risky borrowers, which is reflected in their interest rates. According to this line of reasoning, by limiting interest rates, legislatures can trigger a market response that will actually drive poor consumers out of the market by limiting their access to safe credit. ${ }^{34}$

Another problem with price caps may arise when firms operate in multi-dimensional markets. ${ }^{35}$ Legislatures often focus on specific, salient problems. Policymakers are drawn to visible initiatives, especially those intended to solve pressing problems that receive public attention. ${ }^{36}$ At the same time, unobserved yet rather important initiatives are under-produced. ${ }^{37}$

For instance, annual fees charged by banks are often a relatively salient attribute, so legislatures may seek to impose price caps to reduce these fees. ${ }^{38}$ However, addressing complex problems in isolation may yield misguided inferences. In this context, banks have a strong profit incentive to offset the loss in revenues, preferably by increasing other, non-salient fees. ${ }^{39}$ Thus, banks may respond to annual fee caps by increasing revenues from other dimensions, such as currency conversion fees and rates. Legislatures often fail to effectively address these unintended consequences.

\subsection{Information Disclosures}

The previous example discussed some unintended consequences with respect to the regulation of financial markets. Throughout the analysis, it focused on traders' behaviour. However, policymakers may find it hard to tailor legal interventions to consumers' behaviour as well.

\footnotetext{
33. Bar Gill (2012); Becher, Feldman, Lobel (2019).

34. Pinheiro and Ronen (2016), p. 95-96.

35. Bar-Gill (2015).

36. Romano (2014), p. 27.

37. Romano (2014), p. 27-28.

38. Bar-Gill (2015), p. 469-70.

39. Bar-Gill (2015), p. 469-70.
} 
Consider, for instance, information disclosures. Consumers are assumed to base their decisions on available information. Mandated disclosures can inform consumers and contribute to an efficient market equilibrium. Put simply, information disclosures are assumed to help consumers by bridging informational gaps. Following this logic, legislatures in many countries have been continuously content to propose and enact consumer protection mandated disclosures.

However, mandating information disclosures is a highly contested strategy. First, it is doubtful that legislative bodies can tailor disclosure duties to consumers' individual capabilities and true needs. Often, information disclosures are misaligned with the way consumers absorb and analyse information. ${ }^{40}$ This makes such disclosures unlikely to be read. Moreover, mandating too many disclosures may cause information overload. ${ }^{41}$ Where consumers face large amounts of information, they are unlikely to make good use of it. For these and other reasons, many academics question the wisdom of imposing information disclosure duties. ${ }^{42}$

To use a specific example, let us return to food labelling. Some consumers do read such labels, but many others find them hard to read. ${ }^{43}$ Of those consumers who read food labels, many do not understand the information revealed and do not know how to make use of it. Furthermore, the information is not usually presented in an intuitive and "user-friendly" way. ${ }^{44}$ On top of that, the information is typically presented to consumers when they are in a hurry and beset by other tasks or decisions.

Aside from being costly and perhaps inefficient, food labelling may have another unintended consequence. Retailers realise that packaging is a potential source of information for consumers. Thus, they often transform packaging into another source of enticing marketing-one that attracts consumers' limited attention. ${ }^{45}$ This may worsen the problems associated with information disclosure. More generally, it reflects firms' ability and incentive to meet the formal legal requirements, rather than its spirit. ${ }^{46}$

In addition, legislatures may find it hard to predict consumers' responses to disclosed information due to other contextual reasons. For instance, consumers' belief as to the legislature's motivation may play a crucial role in the former's behaviour. ${ }^{47}$ With disclosures regarding genetically modified

40. Becher (2007), p 167-177; Davis and Davis (1996), p. 279.

41. Ben-Shahar, Schneider (2014), p. 105-106.

42. Hillman (2006), p. 849-50.

43. Black, Rayner (1992), p. 3-9; Jones and Richardson (2007); Grunert K, Wills J, Fernández-Celemín L (2010); https://www.preparedfoods.com/articles/118201-do-consumers-read-the-nutrition-facts-label [accessed 5 March 2020]; https://www.foodnavigator-usa.com/Article/2014/03/03/How-much-do-consumers-use-and-understand-nutrition-labels [accessed 5 March 2020].

44. Jones and Richardson (2007), p. 238.

45. Jones and Richardson (2007), p. 243.

46. Cf. Willis (2015), p. 1327.

47. Bar-Gill, Schkade, Sunstein (2019). 
food (GMOs), consumers may attribute various motivations to legislatures, such as public health or an ideological belief in consumers' right to know. ${ }^{48}$ The perceived motivation, however, plays a crucial role in the way consumers respond to said disclosures. ${ }^{49}$ As the authors of a recent study explain:

Consumers who misperceive the regulator's true motive, or mix of motives, will draw false inferences from the mandated disclosure. If consumers think that the disclosure is motivated by evidence of harm, when in fact it is motivated by a belief in a right-to-know or by interest-group pressure, then they will be inefficiently deterred from purchasing the product. ${ }^{50}$

Research also suggests that trying to warn consumers via disclosures can, in fact, increase the very kind of behaviours they attempt to prevent. Thus, warning labels can increase drinking and driving, ${ }^{51}$ intensify the craving to smoke and inhale more deeply, ${ }^{52}$ or enhance the desire to eat full-fat food. ${ }^{33}$ Such backfiring effects may be explained using Brehm's theory of psychological reactance. ${ }^{54}$ According to this theory, threatening consumers' choice may lead consumers to become more attracted to the threatened attitude or behaviour. ${ }^{55}$

Moreover, disclosures can also backfire by silencing consumers and impacting their "moral calculus of transactional harm". ${ }^{56}$ Experimental research suggests that while disclosures may not influence consumers' behaviour ex-ante, it may nevertheless make consumers less likely to challenge harsh policies. ${ }^{57}$ Put simply, disclosures may lead consumers to view the relevant policies and practices as more legitimate and binding than they are. In consumers' minds, disclosures shift more of the responsibility and blame to themselves.

\subsection{Unhealthy Foods and Addictive Substances}

The discussion of food and GMO labelling leads us next to consider the unintended consequences of regulating unhealthy foods and addictive substances more generally. One major problem with

48. Bar-Gill, Schkade, Sunstein (2019), p. 213.

49. Bar-Gill, Schkade, Sunstein (2019), p. 220.

50. Bar-Gill, Schkade, Sunstein (2019), p. 209.

51. Ringold (2002), p. 51-52.

52. Lindstrom (2008); Siegel (2011).

53. Bushman (1998), p. 99-100.

54. Brehm (1966).

55. Clee and Wicklund (1980), p. 389.

56. Wilkinson-Ryan (2014).

57. Wilkinson-Ryan (2017). 
regulating unhealthy products relates to firms' incentives. If a product is banned, or otherwise regulated, firms may come up with new products to substitute the old.

In a way, this is happening now with the regulation of tobacco products. The U.S. Food and Drug Administration (FDA) initiated a plan that comprehensively regulates tobacco and nicotine products. ${ }^{58}$ In response, firms started selling synthetic nicotine, which "currently fall[s] into a regulatory gap." ${ }^{19}$ This is so because synthetic nicotine products are not considered a "tobacco product" under the relevant legislation. ${ }^{60}$ This, of course, severely undermines the FDA's initiative to combat tobacco products.

Interestingly, the FDA recently launched an anti-vaping campaign titled "The Real Cost". ${ }^{61}$ One problem with this campaign was its dilution in a sea of pro-vaping messages. A study that examined pro- and anti-vaping posts on Instagram found that promotional vaping posts outnumbered the anti-vaping ones in a 10,000 to 1 ratio. ${ }^{62}$ Additionally, the study found that contrary to the FDA's intentions, vaping posts received almost three times more "likes" after the campaign started..$^{63}$ The study also found that the number of vaping posts that had more than 100 likes grew six-fold. ${ }^{64}$ Study participants suggested that while the anti-vaping campaign promoted scare tactics, offering guidance on how to quit vaping would be more effective. ${ }^{65}$

Of course, firms have the incentive to identify loopholes in any regulatory regime that governs their business. Another interesting example that relates to our context is the Health Star Rating (HSR) system, adopted in Australia and New Zealand. The system allows food producers to display a star rating - on a 1 to 5 scale - on their food packaging. Roughly speaking, the HSR is calculated by factoring both healthy and unhealthy ingredients. ${ }^{66}$

Breakfast cereals, for instance, generally contain large quantities of sugar. As such, they could not display an attractive HSR rating. In order to overcome this problem, cereal producers add fiber a "good" ingredient - to offset the large quantities of sugar in their products. ${ }^{67}$ Producers were also able to display a high HSR rating by calculating the healthiness of products on an "as prepared" basis. This allowed a firm to present chocolate milk powder as a healthy product under

58. Zettler, Hemmerich, Berman (2018), p. 1947-51.

59. Zettler, Hemmerich, Berman (2018), p. 1935.

60. Federal Food, Drug, and Cosmetic Act, 21 U.S.C. $\$ 321$ (2012) (defining a tobacco product).

61. https://www.fda.gov/tobacco-products/public-health-education/real-cost-campaign [accessed 5 March 2020].

62. Vassey, Metayer, Kennedy et al (2020).

63. Vassey, Metayer, Kennedy et al (2020).

64. Vassey, Metayer, Kennedy et al (2020).

65. Vassey, Metayer, Kennedy et al (2020).

66. http://www.healthstarrating.gov.au/internet/healthstarrating/publishing.nsf/content/home [accessed 5 March 2020].

67. Becher, Lai, Gao, Harrison (2019). 
the assumption that its consumers would mix the powder with skim milk. ${ }^{68}$ Overall, unbeknownst to consumers, this may increase consumption of unhealthy foods.

A tax increase on beer further illustrates the importance of considering the response of both firms and consumers to legislation. From an economic perspective, increasing the price of beer is likely to reduce its demand and consumption. This is especially true for consumers who are pricesensitive-frequently, teenagers. However, research has shown that while taxing beer indeed reduced consumption by teenagers, these consumers then moved on to consume more cannabis. ${ }^{69}$ Generally speaking, reducing the demand for one unhealthy product may increase demand for another.

Lastly, regulation that is effective in reducing the consumption of an unhealthy food or substance can simultaneously trigger other health-related problems. For example, reducing the consumption of cigarettes may increase obesity rates. ${ }^{70}$ Crafting a sensible policy must consider and weigh such effects.

\subsection{Small Claims Courts}

Consumers face various problems which may limit their access to justice. ${ }^{71}$ They are often unaware of their rights, may not notice the harm they suffer, ${ }^{72}$ and may lack the necessary motivation or resources to complain and rely on their rights. ${ }^{73}$ Consumers may likewise be intimidated by legal procedures, let alone fighting large and powerful corporations in court. ${ }^{74}$ Some consumers may not trust the legal system, and others may experience language and cultural barriers. These and other reasons led many legal systems to introduce small claims courts (or tribunals).

Small claims courts are an important component of the consumer protection landscape. Usually, these courts are less formal and more procedurally flexible. Such courts also allow consumers to bring their cases without paying hefty fees. Moreover, in many small claims courts, representation

\footnotetext{
68. Becher, Lai, Gao, Harrison (2019).

69. DiNardo and Lemieux (2001), p. 994.

70. Tokely (2014), p. 30, n.135.

71. Palmer (2014), p, 496-99.

72. Felstiner, Abel, Sarat (1980-81).

73. Ramsay (1981).

74. Galanter (1974), p. 103.
} 
is not allowed. In short, these courts are believed to be quicker, cheaper, more level, and more convenient for consumers as laypeople. ${ }^{75}$

Firms apparently do not like the idea of appearing in courts without proper legal representation. As it turns out, in some cases, businesses try to outsmart the system, looking for creative solutions. A prominent approach taken by firms is to employ "semi-professionals", such as law students and legal interns, as their legal representatives. ${ }^{76}$ In some countries, this seems to be the prevalent norm. ${ }^{77}$

In an empirical study, we examined the legal outcomes of this practice in relation to litigation over car accident damages. ${ }^{78}$ One sample of cases included individual plaintiffs who sued other individuals. According to the rules that govern small claims disputes, both plaintiffs and defendants were unrepresented. The other sample included cases where individual plaintiffs sued insurance companies, which were represented by said "semi-professionals." All cases were of the same type and nature-minor damages to cars involved in collisions.

Unexpectedly, individual plaintiffs were more successful when suing represented insurance companies than when suing other individuals. ${ }^{79}$ Limiting firms' ability to be legally represented in small claims courts is perceived to be a move that protects consumers and levels the litigation field. However, such a protective measure can actually lower consumers' likelihood to win legal cases.

Other, apparently well-intended, moves in the context of small claims courts may backfire as well. In Ontario, Canada, the legislatures attempted to increase consumers' access to justice by raising the maximum amount allowed in small claims lawsuits. ${ }^{80}$ Unfortunately, this resulted in crowding out smaller disputes, which seemingly need small claims courts as a litigating platform most of all. ${ }^{81}$

\subsection{Cooling-off Periods \& the Right to Exit}

Consumer protection laws also provide consumers with autonomous remedies. An important measure frequently employed by legislatures is cooling-off periods. Such periods enable consumers to cancel or exit transactions, after the fact, at no (or nominal) cost. Some regimes,

\footnotetext{
75. Conley, O’Barr (1990), p. 26-27.

76. Becher and Klein (2010), p. 349.

77. Becher and Klein (2010), p. 349.

78. Becher and Klein (2010), p. 354-66.

79. Becher and Klein (2010), p. 359.

80. Niblett and Yoon (2017), p. 6.

81. Niblett and Yoon (2017), p. 34-35.
} 
such as New Zealand and the United States, allow such "open doors" in rather specific and sometimes narrow circumstances..$^{82}$ Other jurisdictions, such as Israel and the EU, grant consumers more general cooling-off periods. ${ }^{83}$

Providing consumers with cooling-off periods and the right to exit may seem like a sensible approach. Cooling-off periods present consumers with more time to reflect on the transaction they have entered. ${ }^{84}$ This extra time also allows examination of other, competing options. A cooling-off period may grant consumers the opportunity to experience the good or service, thereby learning more about it. ${ }^{85}$ Consumers can thus be sure that the transaction at stake is in line with their preferences.

In addition, where consumers are allowed to exit, sellers have a stronger incentive to provide goods of reasonable quality. Knowing that consumers can cancel the transaction at will, firms are more likely to satisfy consumers' expectations. These rights are also beneficial in terms of consumer choice and competition, since cooling-off periods reduce switching costs. Finally, the very option to cancel a transaction, that is - knowing that one's actions and decisions are reversible, may be psychologically reassuring.

Nevertheless, despite these potential advantages, open doors are often more of a trap than protection. Only a few consumers exercise their cooling-off period rights. ${ }^{86}$ Yet, consumers are likely to overestimate and overvalue open doors. ${ }^{87}$ In short, consumers over-rely on cooling-off periods, while overlooking their limitations and costs. ${ }^{88}$

Moreover, consumers fail to predict the likelihood that they will want to exploit open doors owing to cognitive biases. ${ }^{89}$ After purchasing a good, consumers are prone to overvalue the goods they possess due to the endowment effect and the sunk costs effect. These effects prevent consumers from deviating from previous lines of action. Thus, they diminish consumers' tendencies to cancel or exit transactions.

On top of that, consumers who can reverse their decisions are more preoccupied with them. These consumers are more likely to contemplate possible alternatives and be indecisive with

82. 15 U.S.C. $§ 1635$ (2012); Truth in Lending Act, 15 U.S.C. §§ 1601-1667 (2012); 16 C.F.R. § 429.1 (2018); Fair Trading Act 1986 pt 4A s 36M (NZ).

83. Becher and Zarsky (2010), p. 129-50; Borges and Irlenbusch (2007), p. 85-86.

84. Ben-Shahar and Posner (2011), p. 141-44.

85. Becher and Zarsky (2011).

86. Sovern (2014).

87. Becher and Zarsky (2011), p. 80.

88. Becher and Zarsky (2011), p. 80.

89. Becher and Zarsky (2011), p. 80. 
respect to their purchases..$^{90}$ Thus, consumers who are granted open doors may experience less contentment and more anxiety over their purchasing decisions.

Lastly, in markets with no mandatory right to exit, sellers can grant consumers cooling-off periods to signal quality and reliability. But if open doors are mandatory and imposed across the board, they stop serving as a positive signal. This further undermines consumers' ability to choose wisely among the various products that are being offered in the market. Unfortunately, policymakers overlook the ways open doors undermine, rather than enhance, consumers' welfare.

\section{An Alternative Model of Legislation}

In an attempt to level the playing field, legislatures often introduce well-intended means. But regulating consumer markets is a thorny and complex task. Prominent consumer protection measures - from credit regulation to information disclosures, food labelling, or the mechanics of small claims courts - can backfire and yield unintended negative consequences.

This Part proposes a roadmap for better consumer protection legislation, focusing on four main ideas. The first suggests that regulation should be gradual and moderate. The second recommends engaging in an interdisciplinary cost-benefit analysis, based on empirical evidence and data. The third explores the idea of temporary consumer protection laws. The fourth recommends that administrative agencies and consumer organisations assume a greater role in consumer protection policy and legislation.

\subsection{Gradual and Moderate Legislative Steps}

Revolutions have always sparked human imagination and attention. Our mind is attracted to the unique and the exceptional. Conspicuous occurrences are salient and receive disproportionate attention.

This can impact legislatures in three different ways. First, it may entice legislatures to focus on vivid and remarkable events or problems. This may happen even if such events and problems do not objectively justify the correlating investment of public resources. Second, it can push or incentivise policymakers into proposing grand schemes and "magic bullets" that could appear elegant and clever, and attract public and media attention. Third, it may encourage legislatures to adopt and implement initiatives before sufficient evidence about the initiatives has been gathered.

90. Becher and Zarsky (2011), p. 82. 
Big bangs and overnight solutions are rare. Implementing seemingly bright ideas in the messy, real-world is rarely as easy as it may initially seem. Instead of overnight solutions, much may be said in favour of doing things gradually. ${ }^{91}$

Indeed, significant progress in history has been made incrementally. ${ }^{92}$ For a major change, innumerable minute steps are usually required. ${ }^{93}$ Progress gradually (festina lente) is wise advice, relevant to long-term saving, slimming, meeting sporting challenges, writing projects, and many other spheres..$^{94}$

While some commentators urge judges to adopt an incremental approach, relatively little has been said in favour of incrementalism in legislation..$^{95}$ Interestingly, however, a gradual approach to legislation has been adopted by the Finnish government. ${ }^{96}$ Its legislative design is to enact new laws in stages, meanwhile considering feedback. The idea is to start "small" and "simple"; thereafter, progressing gradually as feedback, data and experiences are gathered.

Consider, for instance, the Finnish approach to the idea of Universal Basic Income. Here, it has been observed that:

The experiment itself is fascinating, not just because of what Finland is testing but also how they are testing it. Finland is trying out a unique, design-oriented way of thinking about government. Rather than rolling out laws on a massive scale, they are trying to craft legislation in stages, with user feedback, just as one would create a piece of design. ${ }^{97}$

To facilitate reaching that end, the Finnish government established an "experimentation unit," which proposes "prototypes of laws." 98 Before applying these more broadly, the legislature seeks to empirically assess the effectiveness of said prototypes. ${ }^{99}$ Thus, the Finnish government decided that it should not begin by revolutionising the welfare system. ${ }^{100}$ Rather, it started by implementing the idea of Universal Basic Income with a random sample of people. ${ }^{101}$

91. Hocking (2011); see also http://freakonomics.com/podcast/in-praise-of-incrementalism/ [accessed 5 March 2020].

92. This is true in math, art, physics, human rights, and many other disciplines. It is also reflected in the idea of "standing on the shoulders of giants."

93. Hirshman (2012).

94. Cf. Kay (2011), p. 187-95.

95. Levmore (2010), p. 816-17.

96. See https://99percentinvisible.org/episode/the-finnish-experiment/ [accessed 5 March 2020].

97. See https://99percentinvisible.org/episode/the-finnish-experiment/ [accessed 5 March 2020]; see also Klein (2016), p. 8.

98. See https://99percentinvisible.org/episode/the-finnish-experiment/ [accessed 5 March 2020].

99. https://99percentinvisible.org/episode/the-finnish-experiment/ [accessed 5 March 2020].

100. https://99percentinvisible.org/episode/the-finnish-experiment/ [accessed 5 March 2020].

101. At the first stage the legislature attempts to examine how Basic Income affects those who receive it. See https://99percentinvisible.org/episode/the-finnish-experiment/ [accessed 5 March 2020]. 
Academics have acknowledged the value of such experiments and trials. ${ }^{102}$ In our context, adopting an incremental approach allows policymakers to focus their attention more effectively. Approaching an issue incrementally reduces the amount and variety of information that needs to be considered. This enhances the prospects of analysing the issue at hand in a more manageable way.

Moreover, many of the problems associated with unintended consequences can be mitigated by an incremental approach to legislation. For instance, legislatures can examine the effects of information disclosures in stages, looking first into the ways consumers and retailers respond to them in a specific market. Only after empirical data and feedback have been gathered should legislatures move on to consider disclosures more generally. The same can be said for enacting cooling-off periods gradually. Overall, such an approach minimises the loss that failures entail, and may generally make the use and implementation of empirical and scientific data more credible. ${ }^{103}$

\subsection{Interdisciplinary, Empirical Approach}

The idea of empirically examining the effects of legislation brings us to our next proposal: incorporating an interdisciplinary, empirical approach to regulation. By using the term "interdisciplinary", we imply engaging people with diverse backgrounds, expertise, and interests. Involving people with different expertise and backgrounds can help meet the need to respond to a constantly changing world.

For example, in regulating the consumption of unhealthy foods, a prudent policy approach might require insights from economists, tax experts, behavioural specialists, nutritionists, health practitioners, historians, food engineers, educators and lawyers. At the same time, policymakers may wish to consider various distinct voices, including groups such as consumers or consumer organisations, producers, importers, traders, and marketers.

Addressing consumer law issues from an interdisciplinary perspective may assist in mitigating some of the hurdles identified above. ${ }^{104}$ First, by engaging people from a range of disciplines and viewpoints, we minimise the likelihood of examining things in isolation. This, in turn, reduces the risk of experiencing unintended consequences. Second, there is a significant body of knowledge that deals with consumer law from various perspectives. An interdisciplinary approach that employs this knowledge decreases the problems associated with lack of institutional expertise. It supplements the legislature and aids its efforts. Third, an interdisciplinary discourse allows more arguments to be balanced and considered, thereby lessening the potential effect of interest groups and lobbyists.

102. Abramowicz, Ayres, Listokin (2011), p. 1005; Romano (2014), p. 28.

103. https://freakonomics.com/podcast/scalability/ [accessed 5 March 2020].

104. See discussion supra Part II. 
Regulation should also strive to be evidence-based, making good use of empirical data and findings. It is tempting and relatively easy to use intuition and common sense. It is also rather enticing to listen to the views of the public or media. But empirical data can correct for individual and public biases, and incorrect assumptions.

Evidence-based decision-making is a vast topic in various disciplines, such as management ${ }^{105}$ and medicine. ${ }^{106}$ Similarly, evidence should inform policy. ${ }^{107}$ Within an evidence-based framework, legislatures are advised to integrate critical thinking and evidence-based information into the legislative process. This can help regulators to think clearly and comprehensively about the challenge they wish to tackle. Next are a few illustrations of how empirical data can impact consumer law policy.

Considering the potential role of empirical findings in relation to GMOs, empirical data can enrich the discussion in at least three ways. First, it can shed light on whether GMOs are dangerous; and if they are, to what degree. Contrary to common beliefs, scientific evidence does not indicate that GMOs are unhealthy. ${ }^{108}$ If legislators ban or discourage the consumption of GMOs due to inaccurate information provided by interested parties, scientific findings may be imperative.

Second, empirical evidence may also shed further light on the possible consequences of not banning or discouraging the consumption of GMOs. For instance, markets that lack GMOs may be more expensive and offer consumers less choice. Alternatively, banning GMOs may result in an overuse of land, an environmental aspect worth considering.

Third, empirical evidence may help policymakers understand how consumers interpret and respond to GMO labelling. Remarkably, one such study found that consumers do not regard GMO labels as warnings. ${ }^{109}$ As noted, another study found that consumers' understanding may depend on what is perceived to be the legislature's intent. ${ }^{110}$ Assuming that policymakers aspire to use GMO labelling to warn consumers, these findings may be invaluable.

Experimental data can also assist regulators in identifying counterintuitive outcomes of seemingly straightforward protective measures. The idea of disclosing actual use patterns provides a specific illustration. Many consumers find mail-in rebates attractive. Yet, most consumers overestimate the probability that they will redeem these rebates, while not utilising them in practice. Thus, it has been suggested that traders should be required to disclose actual redemption rates. The

105. https://www.cebma.org [accessed 5 March 2020].

106. http://www.cebm.net [accessed 5 March 2020].

107. Lunn, Ruane (2013).

108. http://www.who.int/foodsafety/areas_work/food-technology/faq-genetically-modified-food/en/) [accessed 5 March 2020].

109. https://www.uvm.edu/uvmnews/news/new-study-consumers-dont-view-gmo-labels-negative-warnings [accessed 5 March 2020].

110. Bar-Gill, Schkade, Sunstein (2019), p. 209. 
assumption behind this requirement is that equipped with the correct information of low redemption rates, consumers will make smarter decisions. ${ }^{111}$

A controlled experiment in the U.S. sought to examine this hypothesis. ${ }^{112}$ Surprisingly, the authors found that such disclosures had a backfiring, reverse effect. That is, rather than reducing consumers' willingness to purchase products that offer a rebate, these disclosures made such products more attractive to consumers. The culprit, again, is a behavioural bias in the form of overoptimism. The authors opine that while the disclosures inform people about the behaviour and the failure of the average consumer, the majority of people erroneously believe they will perform better than average. ${ }^{113}$

Moving from the US to the EU, the Court of Justice of the European Union has recently considered what information businesses should provide to consumers in relation to the products' country of origin. According to EU law, food producers must indicate the country of origin of foods if a failure to do so might mislead the consumer as to the true country of origin of the food. ${ }^{114}$ The case in hand focused on whether consumers had a right to know whether the products they consumed came from occupied territories that are held by the state of Israel. ${ }^{115}$

As the discussion around GMO labelling reveals, policymakers (and courts) must realise that such information, which appears to be objective and factual, might not be so. Consumers' perceptions vis-à-vis labelling that informs consumers that the product originates from the occupied territories might be more nuanced. Regardless of a product's desirability, consumers may interpret the label as signalling a moral disapproval. If policymakers believe that such a label merely provides factual information that consumers may find important for political or ethical reasons, this belief may be unfounded. Instead, such a label may impact consumers' perspectives.

When it comes to using evidence for law-making, the relatively new field of neuroscience is an exciting venue. Scanning people's minds, reading, and comprehending their responses bears great potential for the law. In fact, this may have a profound impact on the fundamentals of consumer law.

To understand why, recall that policymakers and courts need to determine standards and the scope of protection under consumer law. In forming the boundaries of consumer law, many legislatures employ concepts such as "the average consumer," "the reasonable consumer," "reasonable expectations," and "common sense". In the EU, for example, it is assumed that "the

111. Bar-Gill and Ferrari (2010), p. 109; Sovern (2006), p. 1703.

112. Taha and Mercer (2015).

113. Taha and Mercer (2015).

114. Art 26(2)(a) read in conjunction with art. 9(1)(1) FIR.

115. C-363/18 Organisation juive européenne, Vignoble Psagot Ltd v Ministre de l'Économie et des Finances [2019] ECL 954. 
average consumer" is able to protect her interests when provided with accurate information. ${ }^{116}$ This imaginary "average consumer" is believed to be "reasonably well informed, observant[,] and circumspect" when making decisions. ${ }^{117}$ Accordingly, legislatures need to determine what would be a reasonable level of protection for the ordinary, average consumer.

The EU is not alone in envisaging "reasonable consumers" and numerous other doctrines illustrate the use of general, imprecise standards in the realm of consumer law. One additional example is the New Zealand doctrine of unsubstantiated representations. ${ }^{118}$ According to this doctrine, traders should have "reasonable grounds" to support the representation they make before disseminating them to the public. Yet one general exception to this rule is where the nature of the representation is such "that a reasonable person would not expect [it] to be substantiated." 119

Much ink has been spilled on the use of vague legal norms. Commonly, these norms are called "standards" rather than "rules." Rules are specific, relatively clear, and accurate, and, therefore, provide good guidance. However, legal rules are rigid. Prime examples are deadlines (e.g., for submitting a tax return or making an appeal), age requirements (e.g. for voting, drinking alcohol or driving), minimum wages, and speed limits.

At the same time, standards are open and dynamic norms which allow discretion, flexibility, and adaptations. Yet they do not serve as a good guide of behaviour ex-ante. Terms such as "reasonable," "average," and "common-sense" are legal standards. As such, they facilitate the development of consumer law. Nonetheless, at times they may be too vague, easily manipulated, or ill-fitted. ${ }^{120}$ Standards accord courts much discretion, while judging individuals, occurrences and behaviours only in hindsight.

Strikingly, neuroscience may provide policymakers and judges with empirical data that might render the use of many standards unnecessary. ${ }^{121}$ Brain scans can help determine what consumers think and believe or when they are confused or misled. Neuroscience can demonstrate what exactly the "average" or "reasonable" consumer thinks and believes. Such data is evidently superior to expecting legislatures and judges to intuit consumers' thoughts and minds. Instead of assuming how consumers use their "common-sense," fMRIs can provide accurate assessments of

116. http://www.efr.be/documents/publication/09.2004.02\%20Consumer\%20Protection\%20-

\%20Breaking\%20the\%20deadlock\%201Feb2004.pdf [accessed 6 March 2020], p. 31.

117. http://www.efr.be/documents/publication/09.2004.02\%20Consumer\%20Protection\%20-

\%20Breaking\%20the\%20deadlock\%201Feb2004.pdf [accessed 6 March 2020], p. 31; see

http://ec.europa.eu/justice/consumer-marketing/unfair-trade/unfair-practices/is-it-fair/is-it-unfair/index_en.htm [accessed 6

March 2020].

118. Fair Trading Act 1986, pt 1 s 12A (NZ).

119. Fair Trading Act 1986, pt 1 s 12 A (NZ).

120. Willis (2015), p. 1349-50.

121. Bartholomew (2018). 
consumers' attitudes and responses. ${ }^{122}$ If brain scans reveal exactly what goes on in consumers' minds, legislatures and courts can use this evidence to better align consumer law with the actual protection that consumers need. Under these circumstances, policy guesswork clearly becomes inferior, if not inappropriate.

From a different perspective, consider the General Data Protection Regulation (GDPR), which requires privacy policies to be drafted and communicated using transparent, clear and plain language. ${ }^{123}$ Lawyers typically understand the term "plain language" to be a standard; a general and not well-defined requirement. Indeed, the GDPR, despite being a comprehensive piece of legislation, does not further define its plain language requirement.

However, a variety of linguistic tools can assist in empirically determining whether a text is written in plain language. In a recent study, we examined the readability of EU privacy policies post GDPR employing two of these tools - the Flesch Reading Ease test and the Flesch-Kincaid test. ${ }^{124}$ Reviewing a sample of more than 200 privacy policies of highly popular EU websites, we found that almost all are not readable for the average consumer. This further illustrates how adopting an interdisciplinary and empirical attitude towards what might seem vague legal standards can shed important light on consumer protection legislation and its effectiveness.

A final example demonstrating the importance of an evidence-based consumer protection policy is found in another aspect of the GDPR: consumers' right to protect their privacy by opting-out from data collection. A recent study that examined consumers' actual behaviour found that a nonnegligible number of consumers indeed exercised their right. ${ }^{125}$ However, the reality is more nuanced, and consumers are heterogenous. Thus, the study also found that the remaining consumers are more persistently trackable. The data also indicated that "the average value of the remaining consumers to advertisers has increased, offsetting most of the losses from consumers that opt-out". In short, the GDPR assisted sophisticated consumers but failed to protect the less privacy-conscious consumers, who probably need such protection the most.

\subsection{Temporary Consumer Protection Laws}

An evidence-based consumer law regime, however advantageous, is not a panacea. For starters, much of what we believe today to be true knowledge and correct facts will turn out to be untrue within a few years. This is sometimes dubbed "the half-life of facts" or "the half-life of knowledge." 126 In line with the need for a modest regulatory strategy, we next recommend a

122. Bartholomew (2018), p. 526.

123. GDPR, Article 7, 12.1; Recital 39, 42, 58.

124. Becher, Benoliel (2020).

125. https://papers.ssrn.com/sol3/papers.cfm?abstract_id=3522845\&dgcid=ejournal_htmlemail_consumer:1 aw:ejournal_abstractlink [accessed 6 March 2020]

126. Arbesman (2012). 
legislation regime where temporary legislation is favoured. In essence, temporary laws are automatically terminated unless re-affirmed. ${ }^{127}$

The idea of temporary laws has not gone unnoticed. ${ }^{128}$ Temporary legislation has some advantages as it affords a better opportunity for policymakers "to incorporate a greater quantity and quality of information into legislative judgments." ${ }^{129}$ Temporary legislation may be a way to acknowledge the inherent limits of legislation, as it better facilitates the need to test and experiment. Furthermore, it may well counter and minimise the negative outcomes of the legislative desire and incentive to respond to acute, "hot," topics. But although experienced and discussed in some other domains, the idea of temporary laws has generally been overlooked in the realm of consumer protection.

From yet another related perspective, one of the troubling aspects of misguided legislation and unintended consequences may result from the status quo bias. Once legislatures enact a (consumer protection) law, it is unlikely to be revoked. As manifested in other walks of life, people have a strong bias toward the status quo and a tendency to maintain established courses. ${ }^{130}$

This is also known as the power of inertia. Given the status quo bias, it is easy to see why, once a law is enacted, it is not likely to be revisited and/or revoked. ${ }^{131}$ Revisiting a law consumes energy and requires attention. Not questioning the chosen path is easy and tempting. It economises on our scarce resources and limited mental abilities. ${ }^{132}$

At the same time, revisiting laws can prove quite beneficial. Our knowledge of the world, as well as our societal values and beliefs, are constantly changing. ${ }^{133}$ With the exponential growth in knowledge and research techniques, this reality is only likely to become more and more prevalent. ${ }^{134}$ This provides another justification for enacting consumer protection laws in a cautious, gradual and tentative manner.

To be sure, temporary laws come with a price. People are drawn to surety and feel uncomfortable with uncertainty. Temporary legislation might cause some confusion and reduce players' ability to rely on it. It entails intertemporal legislative dynamics and increased legislative transaction costs. ${ }^{135}$ Yet, enacting and periodically revisiting tentative laws has some promising potential

127. Cf. Gersen (2007).

128. Listokin (2008), p. 522-33; Ginsburg, Masur, McAdams (2014), p. 294; Romano (2014), p. 28.

129. Gersen (2007), p. 248.

130. Kahneman (2011), p. 304-305; Thaler, Sunstein (2008), p. 34-35.

131. Schuck (2014), p. 172-82.

132. Ritov and Baron (1992).

133. Arbesman (2012), p. 30.

134. Gersen (2007), p. 298.

135. Gersen (2007), p. 262-66. 
gains. ${ }^{136} \mathrm{~A}$ series of recurring decisions has significant benefits. It can help legislatures correct mistakes, overcome inertia, and examine new data and unpredicted developments.

\subsection{Diffusing and Delegating Legislative Responsibilities}

We have repeatedly seen that legislatures operate within institutional limitations, exposed to noise and pressure. To minimise the problems that this reality generates, diffusing and delegating legislative responsibilities to more isolated policymakers may be an interesting path to consider. Slightly restated, it may well be that administrative bodies and agencies can participate more forcefully in the legislative process.

Administrative organisations are assumed to be much more isolated from political pressure, lobbying, and interest groups. Of course, such organisations can also fall prey to regulatory capture. However, in the context of consumer organisations, personnel who serve in these bodies are not usually elected by the public. Often, they have relevant expertise and professional backgrounds. Many choose to serve in these organisations to better their society, viewing their roles and efforts as a call and duty. Therefore, these individuals may have a better ability to focus on the important matters that are not necessarily at the forefront of public attention.

In the context of consumer markets, enforcement agencies and public organisations may enjoy a higher degree of expertise. Consumer agencies are constantly exposed to the challenges that consumer markets pose. They often deal with, analyse and aggregate numerous consumers' complaints. Presumably, such bodies also have better access to, and dialogue with, experts. In short, they are positioned at a superior starting point, equipped with better expertise and a more balanced and holistic position.

The idea of according administrative agencies and public organisations with more legislative power well-suits the framework sketched in this chapter. For example, it goes hand-in-hand with the call to advance an impartial, evidence-based consumer law policy. Consider, for instance, the phenomenon of group psychology. Humans are social creatures, and the sense of belonging is an important component of being social. We all belong to various groups. While groups have a lot of value, the pressures they create can be quite significant and lead to remarkable results. ${ }^{137}$

When it comes to political and ideological groups, things can go quite astray in many ways. ${ }^{138}$ Here, the desire to be a loyal member of one's political group can, at times, trump rational thinking and

136. To realize these gains, legislation design should also account for the omission bias, which may cause legislatures not to revisit laws even when enacted temporarily.

137. Asch (1951), p. 177.

138. https://www.psychologytoday.com/us/blog/life-is-trip/201208/you-are-tribal-person [accessed 6 March 2020]. 
distort one's judgement. In other words, when political issues are at stake, many would prefer to adhere to the group's expectations and viewpoint, rather than "getting it right." 139

It is easy to view consumer law policy as a political debate. Key issues relating to regulating markets, adopting paternalistic measures to protect consumers, levelling the consumer-firm playing field, or the degree to which society should hold individuals responsible for their actions and decisions in the marketplace are all influenced by political ideology. Virtually every evidencebased issue in the realm of consumer law policy can become politicised.

At the same time, political attitudes often remain unchanged, even when new facts and information is at hand. Motivated reasoning leads people in general, and politicians in particular, to interpret new information and evidence in ways that support their pre-existing beliefs. ${ }^{140}$ The literature repeatedly demonstrates that people will manipulate the data they encounter so that the data will conform to their already existing beliefs. ${ }^{141}$

Legislatures, pressured by their political group, are likely to exhibit cultural cognition, which is defined as "the tendency of individuals to conform their beliefs about disputed matters of fact ... to values that define their cultural identities". ${ }^{142}$ Rather than examining data impartially, legislatures are prone to base their perceptions and opinions on group beliefs and values. Legislatures are generally not equipped with scientific knowledge and are not trained to pursue precision and accuracy. If the debates over consumer law policy are mainly framed as political, crafting the right legal rules becomes increasingly difficult, if not impossible.

Administrative bodies, however, are more likely to refrain from transferring evidence-based issues into political ones. Consumer organisations, then again, can produce a better environment, where evidence is not easily polluted by political views and values. Such organisations are more professional. They have a better chance to advance an institutional climate where trained people examine data in a more objective and scientific way, outside of political context and group pressure. They are also less likely to experience an institutional gridlock. Moreover, professional bodies are also more likely to overcome the tendency to oversimplify complex issues and "fit them into our preconceived models." ${ }^{143}$ Presumably, they are better positioned to implement and scaleup scientific, empirical and evidence-based findings and interventions in policymaking.

Assuming more of the legislative work should be allocated to administrative bodies, an important preliminary point is the institutions' governance structure. Clearly, the chosen composition, which should have an open and adaptable design, can influence an institution's ability to fulfil its purpose. It may also affect the public's confidence. Of course, determining the optimal composition is a complex task. As a starting point, the analysis above suggests that its members

139. Haidt (2012).

140. Kunda (1990), p. 488; Westen, Blagov, Harenski, et al (2006).

141. http://www.culturalcognition.net [accessed 6 March 2020].

142. http://www.culturalcognition.net [accessed 6 March 2020].

143. Woolley, Chabris, Pentland, et al (2010). 
should ideally include those with expertise in law, economics, psychology, brain studies, wellbeing, consumer behaviour, and marketing.

In this context, it is also worth noting that studies illuminate how to increase group intelligence. ${ }^{144}$ First, the research suggests that collective group intelligence does not seem to be related to factors such as individuals' IQs or the presence of natural leaders. ${ }^{145}$ Instead, the literature identifies three key components that may enhance group intelligence. ${ }^{146}$ The first is equal distribution of contributions. When all group members make roughly the same contribution, overall group intelligence is maximised. ${ }^{147}$ The second is the quality of conversation within the group. If individuals exhibit empathy and ability to read others' moods and feelings, group intelligence will benefit. ${ }^{148}$ In other words, social intelligence or social sensitivity augment group intelligence. ${ }^{149}$ The third vital factor for group intelligence is the inclusion of more women in the group. Generally speaking, the more women in a group, the better its collective intelligence. ${ }^{150}$ Administrative bodies and expert organisations seem to be better positioned than legislatures to utilise these insights.

Last but not least, administrative bodies and consumer organisations are better positioned for crafting innovative regulatory solutions. Overall, they have a more positive approach to change. They have a higher degree of expertise, possess a lot of knowledge, and are less committed to formal, procedural aspects. They may as well be willing to take more risks and test new concepts and ideas.

\section{Conclusion}

Consumer law has had many achievements in advancing better efficiency and fairness in the marketplace. Consumer laws protect consumers from various types of manipulation. It provides consumers with important information. It removes, at least in part, dangerous and risky products from the market.

Along these lines, it has been concluded that:

\footnotetext{
144. Woolley, Chabris, Pentland, et al (2010).

145. Woolley, Chabris, Pentland, et al (2010).

146. Woolley, Chabris, Pentland, et al (2010), p. 688.

147. Woolley, Chabris, Pentland, et al (2010), p. 686, 688.

148. Woolley, Chabris, Pentland, et al (2010), p. 688.

149. Woolley, Chabris, Pentland, et al (2010), p. 686, 688.

150. Woolley, Chabris, Pentland, et al (2010), p. 688.
} 
one of the principal reasons consumer protection regulation has predominantly been a success is that, when such regulation is effectively articulated and enforced, everyone wins: consumers, because of the protection of quality and safety of products and services, and businesses, because of increased consumer trust. ${ }^{151}$

While not ignoring these accomplishments, there is much room for improvement. After surveying some difficulties and pointing to the phenomenon of unintended consequences, this chapter proposed four major changes to the process of consumer law legislation. However concisely presented, together these suggestions may serve only as a starting point for facilitating significant improvements.

The general sentiment reflected in the proposals delineated in this chapter is one of caution and modesty. Carefulness and humbleness, however, should not be confused with despair, inaction, or pessimism. The need for consumer protection is not likely to decrease any time soon. Tradersarmed with knowledge, experience, data, power, and expertise-are likely to pursue any possible opportunity to maximise their bottom line. Consumer protection proponents should, therefore, stay vigilant.

This chapter focused on design principles of consumer legislation. Of course, this is merely part of the puzzle, which should not be viewed in isolation. As markets change, norms evolve, and technologies develop, we may need to re-think our regulatory framework. For starters, online information flows, market reputation mechanisms and public education may all play vital roles in the consumer protection landscape. This may result in a need to redefine the balance between regulating consumer markets and relying on meta-legal mechanisms.

To be sure, none of the recommendations made in this chapter, or their combination, should be viewed as a panacea. Implementing these recommendations requires a significant shift in the way regulators and legislators approach consumer law. Activating these changes will also necessitate a re-thinking of the allocation of public resources.

As in many other areas, clear thinking about regulation demands awareness and practice. It requires thinking about thinking. It necessitates open-mindedness, patience, energy, discipline, and repetition. There are many tricky challenges to consider. But these challenges should not prevent us from advancing the design of consumer law regulation.

I thank William Britton and Alana Harrison for excellent research assistance.

\section{Bibliography}

Abramowicz M, Ayres I, Listokin Y (2011) Randomizing Law. U Penn L Rev 159(4):929-1005.

Arbesman S (2012), The Half-Life of Facts: Why Everything We Know Has an Expiration Date. Current, Maine.

151. Wood (2017). 
Asch S (1951) Effects of Group Pressure Upon the Modification and Distortion of Judgments, in Guetzkow H (ed) Groups, Leadership and Men. Carnegie Press, Pittsburgh.

Bar-Gill O (2012) Seduction by Contract: Law, Economics, and Phycology in Consumer Markets. Oxford University Press, Oxford.

Bar-Gill O (2015) Price Caps in Multiprice Markets. J Legal Stud 44:453-476.

Bar-Gill O, Ferrari F (2010) Informing Consumers About Themselves. Erasmus L Rev 3(2):93-119.

Bar-Gill O, Schkade D, Sunstein C (2019) Drawing False Inferences from Mandated Disclosures. Behav Pub Policy 3(2):209-227.

Bartholomew M (2018) Neuromarks. Minn L Rev 103:521-585.

Baxter T (1994) The UCC Thrives in the Law of Commercial Payment. Loy LA L Rev 28:113-130.

Becher S (2007) Behavioural Science and Consumer Standard Form Contracts. La L Rev 68:117-180.

Becher S (2008) Asymmetric Information in Consumer Contracts: The Challenge That Is Yet to Be Met. Am Bus LJ 45(4):723-774.

Becher S, Benoliel U (2020) Law in Book and Law in Action: Readability of Privacy Agreements and the GDPR, in Mathis K, Avishalom T (eds) Consumer Law and Economics. Springer, New York.

Becher S, Feldman Y, Lobel O (2019) Poor Consumer(s) Law: The Case of High-Cost Credit and Payday Loans, in Gersen J, Steckel J (eds) Cambridge University Press, Cambridge.

Becher S, Klein A (2010) The Paradox of Power and Representation in Small Claims Court? Insurance Claims, Power Gaps and the Judge's Foot. Hapraklit L Rev 50:327-401.

Becher S, Lai J, Gao H, Harrison A (2019) Hungry for Change: The Law and Policy of Food Health Labelling. Wake Forest Law Review 54:1305-1360.

Becher S, Zarsky T (2010) Consumers' Right of Withdrawal: A Well-Reasoned Right or a Pyrrhic Victory? Tel Aviv U L Rev 32:127-203.

Becher S, Zarsky T (2011) Open Doors, Trap Doors, and the Law. L \& Contemp Probs 74:63-94.

Ben-Shahar O, Bar Gill O (2013) Regulatory Techniques in Consumer Protection: A Critique of European Consumer Contract Law. Common Market Law Review 50:109-126.

Ben-Shahar O, Posner E (2011) The Right to Withdraw in Contract Law. J Legal Stud 40(1):115-148.

Ben-Shahar O, Schneider C (2014) More Than You Wanted to Know: The Failure of Mandated Disclosure. Univ Pa Law Rev 159:647-749.

Black A, Rayner M (1992) Just Read the Label: Understanding Nutrition Information in Numeric, Verbal and Graphic Forms. HMSO, London.

Borges G, Irlenbusch B (2007), Fairness Crowded Out by Law: An Experimental Study on Withdrawal Rights. J Institutional \& Theoretical Econ 163(1):84-101.

Boss A (1994) Foreword: "Is the UCC Dead, or Alive and Well? An Introduction to the Practitioners' Perspectives. Loy LA L Rev 28(4):89-100.

Braucher J (1988) Defining Unfairness: Empathy and Economic Analysis at the Federal Trade Commission. B U L Rev 68:349-430.

Bregman R (2014) Utopia for Realists: The Case for a Universal Basic Income, Open Borders, and a 15Hour Workweek. The Correspondent, Amsterdam.

Brehm J (1966) A Theory of Psychological Reactance. Academic Press, New York. 
Bushman B (1998) Effects of Warning and Information Labels on Consumption of Full-Fat, Reduced-Fat, and No-Fat Products. J Applied Psychol 83(1):97-101.

Calabresi G (1982) A Common Law for the Age of Statutes. Harvard University Press, Cambridge.

Chabris C, Simons D (2010) The Invisible Gorilla: How our Intuitions Deceive Us. Harmony, Pennsylvania.

Clee M, Wicklund R (1980) Consumer Behavior and Psychological Reactance. J Consumer Res 6(4):389_ 405.

Conley J, O'Barr W (1990) Rules Versus Relationships: The Ethnography of Legal Discourse. University of Chicago Press, Chicago.

Davis C, Davis E (1996) Information Load and Consistency of Decisions. Psychol Rep 79:279-288.

DiNardo J, Lemieux T (2001) Alcohol, Marijuana, and American Youth: The Unintended Consequences of Government Regulation. J Health Econ 20(6):991-1010.

Eskridge W, Frickey P, Garrett E (2007) Cases and Materials on Legislation, Statutes and the Creation of Public Policy. 4th edn, West Academic Publishing, Minnesota.

Felstiner W, Abel R, Sarat A, (1980-81) The Emergence and Transformation of Disputes: Naming, Blaming, Claiming .... Law \& Society Rev 15(3):631-654.

Galanter M (1974) Why the "Haves" Come Out Ahead: Speculations on the Limits of Legal Change. Law \& Society Rev 9(1):95-160.

Gersen J (2007) Temporary Legislation. U Chi L Rev 74:247-298.

Gillette C (1996) Rules, Standards, and Precautions in Payment Systems. Va L Rev 82(2):181-251.

Gillette C (2005) Pre-Approved Contracts for Internet Commerce. Hous L Rev 42(4):975-1013.

Ginsburg T, Masur J, McAdams R (2014) Libertarian Paternalism, Path Dependence, and Temporary Law. U Chi L Rev 81:291-359.

Goyens M (2018) Using Behavioural Economics For Rather than Against Consumers - A Practitioner's Perspective. Interconomics 53:12-17.

Grunert K, Wills J, Fernández-Celemín L (2010) Nutrition Knowledge, and Use and Understanding of Nutrition Information on Food Labels Among Consumers in the UK. Appetite 55(2):177-189.

Haidt J (2012) The Righteous Mind: Why Good People Are Divided by Politics and Religion. Vintage, Visalia.

Hayek F (1945) The Use of Knowledge in Society. Am Econ Rev 35(4):519-530.

Hillman R (2006) Online Boilerplate: Would Mandatory Website Disclosure of E-Standard Terms Backfire? Mich L Rev 104(5):837-856.

Hirshman L (2012) Victory: The Triumphant Gay Revolution. Harper Perennial, New York.

Hocking W (2011) In Praise of Incremental Steps and Modest Ideas. Physics in Canada 67(3):177-181.

Jones G, Richardson M (2007) An Objective Examination of Consumer Perception of Nutrition Information Based on Healthiness Ratings and Eye Movements. Pub Health Nutrition 10(3):238244.

Kay J (2011) Obliquity: Why Our Goals Are Best Achieved Indirectly. Penguin Books, London.

Klein E (2016) Universal Basic Income. Arena Mag 142:6-8. 
Kripke H (1982) Reflections of a Drafter. Ohio St L J 43:577-584.

Kunda Z (1990) The Case for Motivated Reasoning. Psychol Bull 108(3):480-498.

Letsou P (1995) The Political Economy of Consumer Credit Regulation. Emory LJ 44:587-678.

Levmore S (2010) Interest Groups and the Problem with Incrementalism. U Penn L Rev 158:815-858.

Lindstrom M (2008) Inhaling Fear. New York Times.

Listokin Y (2008), Learning Through Policy Variation. Yale LJ 118(3):480-553.

Lunn P, Frances R (2013) Using Evidence to Inform Policy. Gill \& Macmillan Ltd, Dublin.

Niblett A, Yoon A (2017) Unintended Consequences: The Regressive Effects of Increased Access to Courts. J Empirical Legal Stud 14(1):5-30.

O’Connor G (2001) Rendering to Caesar: A Response to Professor O’Reilly. Admin L Rev 53:343-393.

Palmer J (2014) Access to Justice for Consumers, in Tokeley K (ed) Consumer Law in New Zealand. 2nd ed, LexisNexis, Wellington.

Pinheiro T, Ronen J (2016) Unintended Consequences of the Credit Card Act. J L Fin \& Acct 1:93-138.

Ramsay I (1981) Consumer Redress Mechanisms for Poor-Quality and Defective Products. U Toronto LJ $31: 117-152$.

Ringold D (2002) Boomerang Effect: In Response to Public Interventions: Some Unintended Consequences in the Alcoholic Beverage Market. J Consumer Policy 25(1):27-63.

Ritov I, Baron J (1992) Status-Quo and Omission Biases. J Risk \& Uncertainty 5:49-61.

Roberta R (2014) Regulating in the Dark and a Postscript Assessment of the Iron Law of Financial Regulation. Hofstra L Rev 43(1):25-93.

Rubin E (1993) Thinking Like a Lawyer, Acting Like a Lobbyist: Some Notes on the Process of Revising UCC Articles 3 and 4. Loy LA L Rev 26:743-789.

Schuck P (2014) Why the Government Fails so Often: And How it can do Better. Princeton University Press, Princeton.

Siegel M (2011) Gruesome Cigarette-Pack Warnings Say Too Much. Bloomberg.

Silber N (1997) Substance Abuse at UCC Drafting Sessions. Wash U L Q 75:225-242.

Sovern J (2006) Toward a New Model of Consumer Protection: The Problem of Inflated Transaction Costs. William \& Mary L Rev 47(5):1635-1709.

Sovern J (2014) Written Notice of Cooling-Off Periods: A Forty-Year Natural Experiment in Illusory Consumer Protection and the Relative Effectiveness of Oral and Written Disclosures. U Pitt L Rev 75:333-386.

Stancil P (2008) Assessing Interest Groups: A Playing Field Approach. Cardozo L Rev 29:1273-1318.

Sullivan R, Behncke I, Purushotham A (2010) Why Do We Love Medicines So Much?. 11 EMBO Rep 11(8):572-578.

Taha A, Mercer M (2015) Unintended Consequences: An Experimental Investigation of the (In)Effectiveness of Mandatory Disclosures. Santa Clara L Rev 55(2):405-441.

Tokely K (2014), in Tokeley K (ed) Consumer Law in New Zealand. 2nd ed, LexisNexis, Wellington.

Vassey J, Metayer C, Kennedy C et al (2020) \#Vape: Measuring E-Cigarette Influence on Instagram With Deep Learning and Text Analysis. Fronteirs in Communication 4:1-75. 
Westen D, Blagov P, Harenski K, et al (2006) Neural Bases of Motivated Reasoning: An fMRI Study of Emotional Constraints on Partisan Political Judgment in the 2004 U.S. Presidential Election. J Cognitive Neuroscience 18(11):1947-1958.

Wilkinson-Ryan T (2014) A Psychological Account of Consent to Fine Print. Iowa L Rev 99:1745-1784.

Wilkinson-Ryan T (2017) The Perverse Consequences of Disclosing Standard Terms. Cornell L Rev 103(1):117-175.

Willis L (2015) Performance-Based Consumer Law. U Chi L Rev 82:1309-1409.

Wood J (2017) Consumer Protection: A Case of Successful Regulation, in Drahos P (ed) Regulatory Theory: $\quad$ Foundations and Applications. Australian National University Press, Canberra.

Woolley A, Chabris C, Pentland A, et al (2010) Evidence for a Collective Intelligence Factor in the Performance of Human Groups. SCI 330:686-688.

Zettler P, Hemmerich N, Berman M (2018) Closing the Regulatory Gap for Synthetic Nicotine Products. BC L Rev 59(6):1933-1982.

\section{Websites}

Aridor G, Che Y, Nelson W et al (2020) The Economic Consequences of Data Privacy Regulation: Empirical from Evidence GDPR. Available at https://papers.ssrn.com/sol3/papers.cfm?abstract_id=3522845\&dgcid=ejournal_htmlemail_con sumer:law:ejournal_abstractlink. Accessed 6 March 2020.

CEBM (2018) Centre for Evidence-Based Medicine. CEBM. Available at http://www.cebm.net. Accessed 5 March 2020.

CEBMa (2018) Welcome to the Center for Evidence-Based Management. CEBMa. Available https://www.cebma.org. Accessed 5 March 2020.

Cultural Cognition (2020) The Cultural Cognition Project at Yale Law School, Cultural Cognition. Available at http://www.culturalcognition.net. Accessed 6 March 2020.

Dubner S (2016) In Praise of Incrementalism. Freakonomics. Available at http://freakonomics.com/podcast/in-praise-of-incrementalism/. Accessed 5 March 2020.

Dubner S (2020) Policymaking Is Not a Science (Yet). Freakonomics Radio. Available at https://freakonomics.com/podcast/scalability/. Accessed 5 March 2020.

European Commission (2020) Consumers. Available at http://ec.europa.eu/justice/consumermarketing/unfair-trade/unfair-practices/is-it-fair/is-it-unfair/index_en.htm. Accessed 6 March 2020.

European Financial Services Round Table (2004) Consumer Protection and Consumer Choice, European Financial Services Round Table. Available http://www.efr.be/documents/publication/09.2004.02\%20Consumer\%20Protection\%20

-\%20Breaking\%20the\%20deadlock\%201Feb2004.pdf. Access 6 March 2020.

Fein J (2012) You Are a Tribal Person. Psychology Today. Available at https://www.psychologytoday.com/us/blog/life-is-trip/201208/you-are-tribal-person. Accessed 6 March 2020.

Food and Drug Administration (2020) The Real Cost Campaign. Food and Drug Administration. Available at https://www.fda.gov/tobacco-products/public-health-education/real-cost-campaign. Accessed 5 March 2020. 
Health Star Rating (2020) Health Star Rating. Available at http://www.healthstarrating.gov.au/internet/healthstarrating/publishing.nsf/content/home. Accessed 5 March 2020.

Hennessy M (2014) How Much Do Consumers Use (and Understand) Nutrition Labels? Food Navigator -USA. Available at https://www.foodnavigator-usa.com/Article/2014/03/03/How-much-doconsumers-use-and-understand-nutrition-labels. Accessed 5 March 2020.

Prepared Foods (2016) Do Consumers Read the Nutrition Facts Label? Prepared Foods. Available at https://www.preparedfoods.com/articles/118201-do-consumers-read-the-nutrition-facts-label. Accessed 5 March 2020.

Reidel J (2015) New Study: Consumers Don’t View GMO Labels as Negative 'Warnings,'. UVM Today. Available at https://www.uvm.edu/uvmnews/news/new-study-consumers-dont-view-gmo-labelsnegative-warnings. Accessed 5 March 2020.

Trufelman A (2017) The Finnish Experiment. 99\% Invisible. Available at https://99percentinvisible.org/episode/the-finnish-experiment/. Accessed 5 March 2020.

World Health Org (2014) Frequently Asked Questions on Genetically Modified Foods. World Health Organization. Available at http://www.who.int/foodsafety/areas_work/food-technology/faqgenetically-modified-food/en/. Accessed 5 March 2020. 